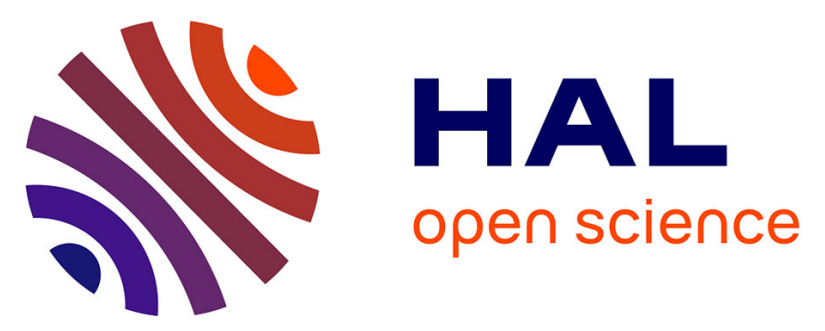

\title{
Consensus guidelines for the optimal management of adverse events in newly diagnosed, transplant-ineligible patients receiving melphalan and prednisone in combination with thalidomide (MPT) for the treatment of multiple myeloma
}

A. Palumbo, F. Davies, M. Kropff, J. Bladé, M. Delforge, F. Costa, R. Garcia Sanz, S. Schey, T. Facon, G. Morgan, et al.

\section{- To cite this version:}

A. Palumbo, F. Davies, M. Kropff, J. Bladé, M. Delforge, et al.. Consensus guidelines for the optimal management of adverse events in newly diagnosed, transplant-ineligible patients receiving melphalan and prednisone in combination with thalidomide (MPT) for the treatment of multiple myeloma. Annals of Hematology, 2010, 89 (8), pp.803-811. 10.1007/s00277-010-0925-1 . hal-00535129

HAL Id: hal-00535129

https://hal.science/hal-00535129

Submitted on 11 Nov 2010

HAL is a multi-disciplinary open access archive for the deposit and dissemination of scientific research documents, whether they are published or not. The documents may come from teaching and research institutions in France or abroad, or from public or private research centers.
L'archive ouverte pluridisciplinaire HAL, est destinée au dépôt et à la diffusion de documents scientifiques de niveau recherche, publiés ou non, émanant des établissements d'enseignement et de recherche français ou étrangers, des laboratoires publics ou privés. 


\title{
Consensus guidelines for the optimal management of adverse events in newly diagnosed, transplant-ineligible patients receiving melphalan and prednisone in combination with thalidomide (MPT) for the treatment of multiple myeloma
}

\author{
A. Palumbo • F. Davies $\cdot$ M. Kropff • J. Bladé • \\ M. Delforge $\cdot$ F. Leal da Costa $\cdot$ R. Garcia Sanz • \\ S. Schey • T. Facon • G. Morgan • P. Moreau
}

Received: 15 December 2009 / Accepted: 8 February 2010/Published online: 16 March 2010

(C) Springer-Verlag 2010

\begin{abstract}
Thalidomide has received approval from the European Agency for the Evaluation of Medicinal Products for the treatment of newly diagnosed multiple myeloma (MM) patients older than 65 years or ineligible for transplant. The results of five phase III trials assessing thalidomide in combination with melphalan and prednisone (MPT) have demonstrated significantly improved response rates compared with melphalan and prednisone (MP) alone. Additionally, two of these studies showed that survival was extended by approximately 18 months in patients treated with MPT compared with MP alone. Thalidomide, in combination with MP, is associated with adverse events (AEs) including peripheral neuropathy and venous thromboembolism. In order to optimize the efficacy of MPT, a good awareness of these AEs is imperative. This manu-
\end{abstract}

\author{
A. Palumbo $(\bowtie)$ \\ University of Torino, \\ Turin, Italy \\ e-mail: appalumbo@yahoo.com \\ F. Davies $\cdot$ G. Morgan \\ Institute of Cancer Research and Royal Marsden Hospital, \\ Sutton, UK \\ M. Kropff \\ University Clinic of Muenster, \\ Muenster, Germany \\ J. Bladé \\ Hospital Clinic, IDIBAPS, Institut Clinic de Malaties \\ Hematologiques i Oncologiques, \\ Barcelona, Spain \\ M. Delforge \\ Catholic University, \\ Leuven, Belgium
}

script outlines both evidence- and consensus-based recommendations discussed by a panel of experts, to provide a practical guide for physicians addressing the effective management of newly diagnosed, transplant-ineligible MM patients receiving thalidomide therapy.

Keywords Myeloma $\cdot \mathrm{MM} \cdot$ Thalidomide $\cdot$ Treatment guidelines

\section{Introduction}

Multiple myeloma (MM) is a hematologic cancer of the plasma cells, which results in bone destruction and marrow failure, potentially leading to osteolytic lesions alongside

F. Leal da Costa

Portuguese Institute of Oncology,

Lisbon, Portugal

R. Garcia Sanz

Hospital Universitario de Salamanca,

Salamanca, Spain

S. Schey

King's College Hospital,

London, UK

T. Facon

Lille University Hospital,

Lille, France

P. Moreau

University of Nantes,

Nantes, France 
cytopenia-related bacterial infections and anemia $[1,2]$. MM is primarily a disease of the elderly, with $70 \%$ of patients 65 years or older at diagnosis [1]. This trend has notable implications for the pharmacological management of MM: high-dose chemotherapy and stem cell transplantation are the conventional treatments for MM patients younger than 65 years, with adequate performance status and organ function [1], and this approach may not be suitable for older MM patients or those with concomitant disease.

Although the combination of oral melphalan and prednisone (MP) has been the standard front-line therapy for $\mathrm{MM}$ for more than four decades in older transplantineligible patients [2], outcomes in this group remain suboptimal. A meta-analysis has suggested that conventional combination chemotherapy offers no survival advantage over MP [3], leading to growing interest in other novel agents such as thalidomide, lenalidomide, and bortezomib.

Following positive results in the relapsed/refractory setting [4-6], five phase III studies assessing thalidomide in combination with MP (MPT), in newly diagnosed elderly patients ineligible for transplant, have been undertaken: the Italian Multiple Myeloma Study Group (GIMEMA) study, two studies from the Intergroupe Francophone du Myelome (IFM 99-06 and IFM 01-01), the study conducted by the Nordic Myeloma Study Group and the Dutch Haemato-Oncology Cooperative Group (HOVON) 49 study [7-12]. In these studies, MPT demonstrated significantly improved response rates compared with MP. Moreover, survival was prolonged by approximately 18 months in patients receiving thalidomide compared with MP alone in the IFM studies [8, 9]. However, in the GIMEMA, Nordic and HOVON 49 studies, while improved response rates did not result in an overall survival benefit $[7,10-12]$, the addition of thalidomide resulted in a longer median progression-free survival in the GIMEMA study [12] and a superior eventfree survival in the HOVON 49 study [11].

On the basis of these data, MPT has been approved by the European Agency for the Evaluation of Medicinal Products for the treatment of newly diagnosed MM patients older than 65 years or ineligible for transplant and is also recommended for this treatment group by the National Comprehensive Cancer Network (NCCN) and Mayo Clinic guidelines $[2,13]$.

In order to optimize the clinical effectiveness of MPT therapy, it is imperative to have a good awareness of the associated adverse events (AEs) and to have strategies in place on how best to manage them. To achieve this, an expert panel of hematologists convened to address the key issues when treating newly diagnosed patients with MPT and to provide recommendations to ensure optimal patient outcomes. This manuscript outlines both evidenceand consensus-based recommendations discussed by the panel, to provide a practical guide for physicians addressing the effective management of newly diagnosed, transplant-ineligible MM patients receiving thalidomide therapy.

\section{Optimizing treatment through side effect management}

Thalidomide is likely to be prescribed in combination with MP for up to 18 months [14]. Therefore, optimizing quality of life through a good understanding and management of potential treatment-related AEs is essential.

Thalidomide, in combination with MP, is associated with hematological side effects (neutropenia, anemia, thrombocytopenia), thromboembolic side effects, and nonhematologic side effects, including peripheral neuropathy,
Table 1 Easily manageable adverse events

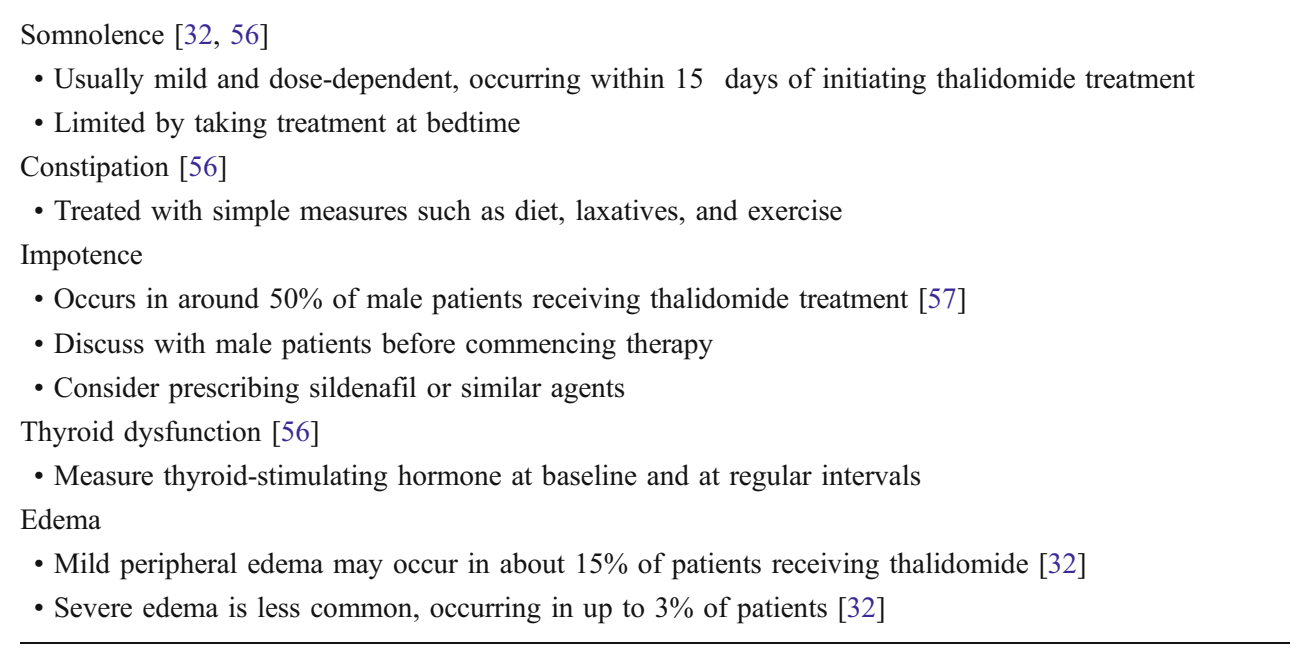


somnolence/fatigue, constipation, arrhythmias [7,8], and cutaneous reactions [7]. In MM patients, some of these AEs (such as neutropenia, thrombocytopenia, fatigue, and thromboembolic events) are also seen with the thalidomide analog, lenalidomide [15].

Some AEs reported in relation to thalidomide are relatively well known (see Table 1) while others are less common. It is important to be able to recognize these as early as possible so that appropriate management strategies can be implemented and thalidomide treatment can be optimized.

Thromboembolic events

Venous thromboembolism (VTE) is a critical clinical condition manifesting as deep vein thrombosis (DVT) and/or pulmonary embolism (PE) [16]. The annual incidence is $>1$ per 1,000 in the general population [17] with one third of all cases of VTE presenting as sudden death [18]. This is of particular importance in MM patients because, although the risk of VTE is higher among cancer patients versus the general population [19], it is further increased with hematologic malignancies [20].

Thalidomide is a convenient oral therapy that avoids the potential complications of long-term central venous catheter use, such as infection and line-related throm- bosis [21]. However, thalidomide treatment is associated with an increased risk of VTE, especially when used in combination with dexamethasone [22] and/or chemotherapy [23-25] - the risk is generally greatest in patients treated with thalidomide in the first-line, as opposed to the relapsed/refractory setting (Table 2). There is also evidence to suggest that the risk of developing VTE with thalidomide therapy is influenced by genetic and environmental factors [26].

In the IFM 99-06 and GIMEMA studies of MPT in the first-line treatment of newly diagnosed, transplantineligible MM patients, the occurrence of DVT and PE was highest during the first 4 months of MPT therapy $[7,8]$. It is essential to identify patients at risk of thromboembolic complications and use appropriate prophylaxis to reduce their incidence. Risk factors for VTE are summarized in Table 3. It is noteworthy that, since the incidence of $\mathrm{MM}$ is increased in the elderly with the majority of patients older than 60 years [1], age has not been not included as a risk factor. Thromboprophylaxis is mandatory in patients receiving MPT, who should be assessed for VTE risk factors prior to initiating MPT therapy (Fig. 1). The presence of at least one risk factor in addition to MM confers a high risk of developing thromboembolic complications, and prophylactic low molecular weight heparin (LMWH) is advised in these circumstances. However, as LMWH requires daily intravenous

Table 2 Venous thromboembolism incidence in trials of thalidomide without thromboprophylaxis

\begin{tabular}{|c|c|c|c|c|}
\hline \multirow{2}{*}{$\begin{array}{l}\text { Treatment } \\
\text { regimen }\end{array}$} & \multicolumn{2}{|c|}{ Newly diagnosed patients } & \multicolumn{2}{|c|}{ Relapsed/refractory patients } \\
\hline & VTE incidence (\%) & References & VTE incidence (\%) & References \\
\hline \multicolumn{5}{|l|}{ Thalidomide } \\
\hline Alone & $3-4^{\mathrm{a}}$ & $\begin{array}{l}\text { Rajkumar et al. } 2003 \text { [58]; } \\
\text { Weber et al. } 2003 \text { [59] }\end{array}$ & $2-4$ & $\begin{array}{l}\text { Barlogie et al. } 2001 \text { [5]; Neben et al. } \\
2002 \text { [67]; Schey et al. } 2003 \text { [68] }\end{array}$ \\
\hline $\begin{array}{l}\text { Plus } \\
\text { dexamethasone }\end{array}$ & $14-26$ & $\begin{array}{l}\text { Rajkumar et al. } 2006 \text { [60]; Cavo et al. } \\
2004 \text { [61]; Rajkumar et al. } 2002 \text { [62] }\end{array}$ & $2-8$ & $\begin{array}{l}\text { Anagnostopoulos et al. } 2003 \text { [69]; } \\
\text { Palumbo et al. } 2004 \text { [70] }\end{array}$ \\
\hline Plus doxorubicin & $10-27$ & $\begin{array}{l}\text { Osman et al. } 2001 \text { [63]; Schutt et al. } \\
2005 \text { [25]; Zervas et al. } 2004 \text { [64] }\end{array}$ & $58^{\mathrm{b}}$ & Baz et al. $2005[71]$ \\
\hline $\begin{array}{l}\text { Plus } \\
\text { cyclophosphamide }\end{array}$ & $3^{\mathrm{b}}-11$ & $\begin{array}{l}\text { Sidra et al. } 2006[53] \\
\text { Wu et al. } 2006[65]\end{array}$ & $4-8$ & $\begin{array}{l}\text { Dimopoulos et al. } 2004 \text { [72]; } \\
\text { Garcia-Sanz et al. } 2004 \text { [38]; } \\
\text { Kropff et al. } 2003 \text { [73]; } \\
\text { Suvannasankha et al. } 2007 \text { [74] }\end{array}$ \\
\hline $\begin{array}{l}\text { Plus melphalan } \\
\text { and prednisone }\end{array}$ & $12-17$ & $\begin{array}{l}\text { Palumbo et al. 2006; [7] Facon et al. } \\
2007 \text { [8] }\end{array}$ & NA & \\
\hline $\begin{array}{l}\text { Plus multiagent } \\
\text { chemotherapies }\end{array}$ & $3-34$ & $\begin{array}{l}\text { Barlogie et al. } 2006 \text { [66]; } \\
\text { Zangari et al. } 2002[23]\end{array}$ & 15 & Lee et al. 2003 [75] \\
\hline
\end{tabular}

Note: adapted from Palumbo et al. 2008 [16]

$V T E$ venous thromboembolism, $N A$ not applicable

${ }^{a}$ Asymptomatic newly diagnosed multiple myeloma patients

${ }^{\mathrm{b}}$ Both at diagnosis and relapse 
Table 3 Risk factors for venous thromboembolism in patients diagnosed with multiple myeloma
Risk factor (age is excluded)

High-dose dexamethasone (further increased when thalidomide is used in combination with chemotherapy) Comorbidities, such as diabetes or infections

Active cardiovascular disease

Immobility

Prior history of thromboembolic events

Use of erythropoietic agents or other agents such as hormone replacement therapy

Anthracycline treatment

Central venous catheter injections, aspirin is more suitable for those patients with a low risk of VTE.

\section{Recommendations for thromboprophylaxis}

- Thromboprophylaxis is mandatory for patients receiving MPT

- Assess patients for VTE risk factors

- Low- and high-risk patients should be differentially treated:

$\circ$ High-risk:

- LMWH, 40 mg enoxaparin or equivalent [27]

- Duration, 4-6 months

○ Low-risk:

- Aspirin, $100 \mathrm{mg}$ advised although more evidence required [27]

- Duration: as required during the full treatment period plus 30 days after discontinuation

- Patients already receiving anticoagulation should remain on their current medication, providing it is appropriate

\section{Hematologic side effects}

The occurrence of cytopenias has been noted in patients receiving MP therapy $[7,8,28]$; the addition of thalidomide to this regimen results in grade 3-4 thrombocytopenia in 3-14\% of patients, and grade 3-4 neutropenia and anemia in 16-48\% and $3-14 \%$ of patients, respectively [7, 8]. Fatigue, bleeding, and infections are associated with anemia, thrombocytopenia, and neutropenia, respectively, and can therefore have a negative impact on patients' quality of life.

The two IFM studies have reported a higher incidence of grade 3-4 neutropenia with MPT compared with MP alone (48\% vs $26 \%$, respectively, in the IFM 99-06 study and $23 \%$ vs $9 \%$, respectively, in the IFM $01-01$ study) $[8,9]$, although this did not result in an increased infection rate in the IFM 99-06 study [8]. On the basis of these data, it is recommended that hematologic counts are undertaken prior to MPT commencement, with treatment postponement and dose reductions in cases of low counts.

\section{Hematologic recommendations}

- Hematologic assessment prior to starting a new cycle of MPT:

- Minimal acceptable hematologic counts:

- $1,500 / \mu \mathrm{L}$ neutrophils

- 75,000/ $\mu \mathrm{L}$ platelets

- If hematologic counts are low:

- Delay treatment for 2 weeks and reassess blood counts before proceeding to the next treatment cycle

- Reduce thalidomide dose when treatment is reinitiated

- 200-100-50 mg/day to $50 \mathrm{mg}$ every other day

- Melphalan dose should be reduced from $0.25 \mathrm{mg} / \mathrm{kg}$ to $0.18 \mathrm{mg} / \mathrm{kg}$ to $0.10 \mathrm{mg} / \mathrm{kg}$

- Use of granulocyte colony stimulating factor (G-CSF) recommended
Fig. 1 Flow chart for thromboprophylaxis in multiple myeloma patients receiving first-line MPT treatment. MPT thalidomide in combination with melphalan and prednisone, $L M W H$ low molecular weight heparin

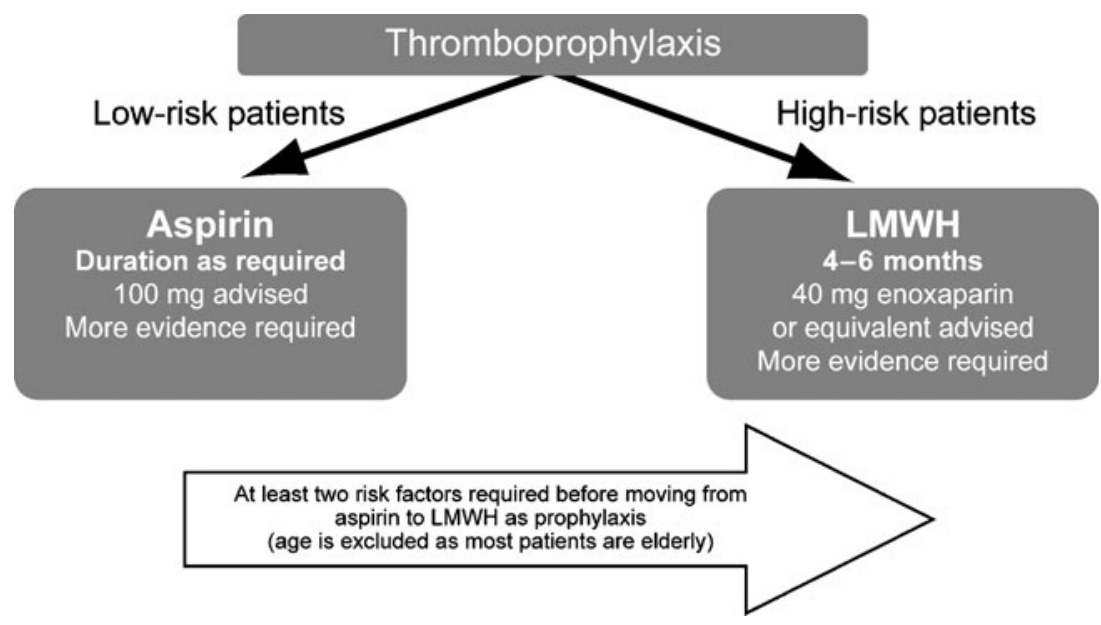


Peripheral neuropathy

Peripheral neuropathy (PNP) can be associated with the MM disease process, occurring in approximately $13 \%$ of patients prior to initiation of thalidomide therapy [29]. It is also known to be a side effect of several agents used in the treatment of MM, including thalidomide [7-9] and bortezomib [30, 31]. The symptoms of PNP noted with thalidomide include numbness, tingling, discomfort, and abnormal coordination or weakness. Careful management is required as these can be irreversible [32]. Bortezomib-associated PNP is characterized by pain, paresthesia, burning dysesthesia, and numbness, with feet more often affected than hands [30]. Prevalence appears to increase with cumulative dose and is irreversible in $29 \%$ of patients [31].

With the MPT combination, grade 3-4 PNP has been reported in $6-8 \%$ of patients $[7,8]$, although in patients $\geq 75$ years, the incidence of grade 2-4 PNP has been reported as $18 \%$ [9]. The incidence and severity are likely to be related to dose and duration of treatment [32-34], although this is disputed in some studies [29]. There is also some debate as to time of onset; in the GIMEMA study of first-line MPT, grade 3-4 PNP was reported after a median of 8 months, while grade 2 PNP led to reductions in thalidomide dose after a median of 5.8 months [7]. However, there have also been reports of PNP after shorter-term use. In one study of newly diagnosed patients receiving thalidomide therapy alone (200 mg/day), PNP occurred as early as 4 months in approximately $66 \%$ of patients and in all patients by 7 months [29]. It is recommended that patients are assessed prior to and at regular intervals during treatment so that the dose of thalidomide can be reduced if PNP develops (Table 4).

\section{PNP recommendations}

- Clinical assessment of all newly diagnosed patients prior to treatment commencement, although nerve conduction studies are not required

- Patient education is important to ensure early detection of PNP

○ Patient perceptions are key; different patients are willing to accept varying degrees of PNP at different stages of disease. Physicians should ensure that this is fully discussed

- Regular clinical assessment for symptoms of PNP to evaluate changes in patients' symptoms; the majority of patients will develop PNP given sufficient length of treatment with thalidomide [34]
Teratogenicity and the risk management plan for pregnancy

Teratogenicity is the most widely known side effect of thalidomide. Thalidomide is absolutely contraindicated in women who are, or could become, pregnant. Therefore, access to the drug in most countries requires participation in a risk management plan to ensure appropriate precautions are taken.

\section{Bradycardia and syncope}

Bradycardia is associated with dizziness, weakness, or syncope while more severe forms can lead to convulsions or sudden cardiac death. Thalidomide-induced bradycardia has been observed in patients with comorbidities or concurrent medications that decrease heart rate [35] and in some situations may require the placement of a pacemaker to alleviate symptoms [36]. Thalidomide is associated with additional non-thrombotic cardiovascular effects [37, 38] with grade 3-4 cardiac toxicity observed in $7 \%$ of patients receiving thalidomide in combination with bortezomib and prednisone [39]. A cardiologic examination by the consulting a hematologist is therefore recommended for all patients prior to commencing thalidomide treatment and monitoring should be carried out during therapy so that the dose can be modified if bradycardia is apparent.

\footnotetext{
Recommendations for bradycardia and syncope

- Cardiologic assessment for all patients prior to commencing therapy -Monitor for bradycardia

$\circ$ Dose reduction or discontinuation of thalidomide may be required
}

\section{Cutaneous reactions}

Skin rashes are frequent complications with thalidomide treatment [40]; minor-moderate skin reactions have been reported in $46 \%$ of patients [40] with case reports of more serious toxic epidermal necrolysis [41, 42] and morbilliform rash [43]. Grade 3-4 dermatologic side effects were reported in $3-6 \%$ of patients receiving MPT in the GIMEMA study, with

Table 4 Recommended dose modifications for thalidomide-related neuropathy in first-line treatment of MM [14]

\begin{tabular}{ll}
\hline Severity of neuropathy & Modification of dose and regimen \\
\hline Grade 1 (paresthesia, weakness, and/or loss of & $\begin{array}{l}\text { Continue to monitor the patient with clinical examination. Consider reducing dose by up to } \\
50 \% \text { if symptoms worsen. } \\
\text { reflexes) with no loss of function }\end{array}$ \\
$\begin{array}{l}\text { Reduce dose by up to } 50 \% \text {, or interrupt treatment and continue to monitor the patient with } \\
\text { activities of daily living) }\end{array}$ & $\begin{array}{l}\text { clinical and neurological examination. If no improvement or worsening of the neuropathy } \\
\text { continues, discontinue treatment. If the neuropathy resolves to Grade } 1 \text { or better, the } \\
\text { treatment may be restarted at } 50 \% \text { of the last dose, if the benefit/risk is favorable. }\end{array}$
\end{tabular}

Grade 3 (interfering with activities of daily living)

Grade 4 (neuropathy which is disabling)

Discontinue treatment.

Discontinue treatment. 
one case of toxic epidermal necrolysis [7, 12]. Steroids have been associated with cutaneous reactions [44] and should be discounted as causative agents prior to modifying the dose of thalidomide. In situations where cutaneous reactions are related to thalidomide, a dose modification is recommended.

\section{Recommendations for cutaneous reactions}

- In grade 3 non-hematological AEs, such as cutaneous reactions, treatment should be discontinued until the severity is reduced to grade 1 at which point treatment can be restarted at $50 \%$ of the original dose

- The exception is cases of toxic reactions such as Stevens-Johnson Syndrome where treatment with thalidomide should be permanently discontinued [14]

Other considerations

\section{Patients with renal impairment}

Renal impairment is common in MM patients, occurring in $20-40 \%$ of patients at presentation depending on the method used for defining renal function [45]. Data from pharmacokinetic studies in MM patients with varying degrees of renal impairment and in patients with end-stage renal disease, suggest that kidney function has no impact on thalidomide pharmacokinetics and therefore dose reductions in patients with renal impairment are not necessary [46]. However, patients with severe organ impairment should be carefully monitored for adverse reactions. Further investigations are needed in patients with renal impairment. In contrast, lenalidomide is predominantly eliminated via urinary excretion of the unchanged drug with renal clearance directly proportional to renal function [47]. Therefore, dose reduction should be considered in patients with moderate/severe renal impairment [47]. Administration of thalidomide in patients with renal failure can increase the risk for bradycardia [48].

Dose adjustment for elderly patients ( $>75$ years)

The optimum dose of thalidomide in different patient groups is not yet well defined [49]; this may be an issue in patients aged $>75$ years where the higher incidence of side effects could be of concern [10]. A lower thalidomide dose of $100 \mathrm{mg} /$ day in combination with MP in the IFM 01-01 study showed positive results, compared with MP alone, in patients aged $>75$ years. This suggests a dose of $100 \mathrm{mg} /$ day thalidomide may be appropriate for the treatment of patients $>75$ years with newly diagnosed MM [9].

\section{Recommendations for dose reductions in elderly patients ( $>75$ years)}

- $100 \mathrm{mg}$ per day of thalidomide may be the most appropriate dose for patients with MM aged $>75$ years old

$\circ$ Dose reduction to $50 \mathrm{mg} /$ day may be required in the event of adverse effects

\section{Conclusions}

MPT is now considered to be an effective standard of care for newly diagnosed, transplant-ineligible patients [2, 13]. A number of AEs are associated with MPT, although these are generally manageable. Somnolence and constipation are common side effects associated with MPT [7, 8], while DVT and peripheral neuropathy are potentially the most serious. As clinical trials addressing thromboprophylaxis are limited, the recommendations in this paper are based on consensus opinion. Therefore, prospective randomized trials comparing the use of different thromboprophylactic regimens (aspirin, LMWH, and warfarin) will help determine the optimal prophylactic strategy for patients with MM being treated with MPT.

Other novel agents, such as lenalidomide and bortezomib, have also shown promising results for MM patients. In a recent phase I/II trial, $81 \%$ of newly diagnosed MM patients receiving lenalidomide in combination with MP (MPR) achieved at least a partial response, with 1-year event-free survival and overall survival rates of $92 \%$ and $100 \%$, respectively [15]. Bortezomib in combination with MP improved survival compared with MP alone, in a phase III trial of newly diagnosed, transplant-ineligible MM patients [50]. It is interesting to note that lenalidomide, in combination with dexamethasone, is effective in patients regardless of prior thalidomide treatment, although overall response rate and complete response rate were higher in thalidomide-naïve patients compared with thalidomideexposed patients with longer median time to progression and longer progression-free survival [51]. In patients receiving bortezomib, in combination with pegylated liposomal doxorubicin, the response rates and duration of response are comparable in patients whether or not they have received prior thalidomide treatment [52]. Therefore, these novel agents could be effective options for the second-line treatment of patients, following MPT therapy.

Cyclophosphamide, thalidomide, and dexamethasone (CTD) is also effective in the treatment of newly diagnosed, transplant-ineligible patients [53]. As with MPT, this contains a combination of an alkylating agent, a steroid and thalidomide. It is therefore likely that the strategies for managing AEs documented here may also be applicable to those associated with CTD.

Studies of cytogenetic abnormalities indicate that MM is heterogeneous with the translocations $\mathrm{t}(4 ; 14)$ or $\mathrm{t}(14 ; 16)$, deletion of chromosome 13 or p53 deletion defining high-risk prognostic groups [54]. Recent data suggest that thalidomide treatment is associated with significantly improved survival in newly diagnosed myeloma patients with metaphase cytogenetic abnormalities compared with control treatment $(P=0.02)$ [55]. In the future, it is likely that further studies will identify subgroups of patients who might benefit most 
from thalidomide-based regimens. These risk-adapted approaches will lead to further improvements in response and survival rates and refine patient management.

After over four decades, thalidomide is the first drug to improve response rates and prolong the duration of remission and survival in patients with MM. The MPT combination offers an effective new approach for transplant-ineligible patients; this efficacy can be maximized through a good awareness of the strategies for optimal patient management. Physician and patient education is key to enabling discussion of practical strategies which would optimize clinical outcomes in transplantineligible patients treated with MPT.

Acknowledgments Research support was provided by Celgene Ltd. Editorial support was provided by Dr. Marion James from ScopeMedical Ltd, funded by Celgene Ltd.

\section{References}

1. Smith A, Wisloff F, Samson D (2005) Guidelines on the diagnosis and management of multiple myeloma 2005. Br J Haematol 132:410-451

2. Anderson KC. NCCN Clinical Practice Guidelines 2008

3. Myeloma Trialists' Collaborative Group (1998) Combination chemotherapy versus melphalan plus prednisone as treatment for multiple myeloma: an overview of 6,633 patients from 27 randomized trials. J Clin Oncol 16:3832-3842

4. Singhal S, Meta J, Disakan R et al (1999) Antitumor activity of thalidomide in refractory multiple myeloma. $\mathrm{N}$ Engl $\mathrm{J}$ Med 341:1565-1571

5. Barlogie B, Disikan R, Eddlemon P et al (2001) Extended survival in advanced and refractory multiple myeloma after single-agent thalidomide: identification of prognostic factors in a phase 2 study of 169 patients. Blood 98:492-494

6. van Rhee F, Dhodapkar M, Shaughnessy JD Jr et al (2008) First thalidomide clinical trial in multiple myeloma: a decade later. Blood 112:1035-1038

7. Palumbo A, Bringhen S, Caravita T et al (2006) Oral melphalan and prednisone chemotherapy plus thalidomide compared with melphalan and prednisone alone in elderly patients with multiple myeloma: randomised controlled trial. Lancet 367:825-831

8. Facon T, Mary JY, Hulin C et al (2007) Melphalan and prednisone plus thalidomide versus melphalan and prednisone alone or reduced-intensity autologous stem cell transplantation in elderly patients with multiple myeloma (IFM 99-06): a randomised trial. Lancet 370:1209-1218

9. Hulin C, Virion J, Leleu X et al (2009) Efficacy of melphalanprednisone-thalidomide (MP-T) to melphalan-prednisone (MP) in patients 75 years of age or older with untreated multiple myeloma (MM). Preliminary results of the randomized, double-blind, placebo controlled IFM 01-01 trial. J Clin Oncol 27: 3664-3670

10. Waage A, Gimsing P, Juliusson G et al (2007) Melphalanprednisone-thalidomide to newly diagnosed patients with multiple myeloma: a placebo controlled randomised phase 3 trial. ASH Annual Meeting abstracts Blood 110:78

11. Wijermans P (2009) Melphalan + prednisone versus melphalan + prednisone + thalidomide in induction therapy for multiple myeloma in elderly patients: final analysis of the Dutch Cooperative Group HOVON 49 study. Blood 112. Abstract 649
12. Palumbo A, Bringhen S, Liberati AM et al (2008) Oral melphalan, prednisone and thalidomide in elderly patients with multiple myeloma: updated results of a randomized controlled trial. Blood 112:3107-3114

13. Dispenzieri A, Rajkumar SV, Gertz MA et al (2007) Treatment of newly diagnosed multiple myeloma based on Mayo Stratification of Myeloma and Risk-adapted Therapy (mSMART): consensus statement. Mayo Clin Proc 82:323-341

14. Thalidomide Celgene SmPC (2008)

15. Palumbo A, Falco P, Corradini P et al (2007) Melphalan, prednisone and lenalidomide treatment for newly diagnosed myeloma: a report from the GIMEMA - Italian multiple myeloma network. J Clin Oncol 25:4459-4465

16. Palumbo A, Rajkumar SV, Dimopoulos MA et al (2008) Prevention of thalidomide- and lenalidomide-associated thrombosis in myeloma. Leukemia 22:414-423

17. Silverstein MD, Heit JA, Mohr DN et al (1998) Trends in the incidence of deep vein thrombosis and pulmonary embolism: a 25-year population-based study. Arch Intern Med 158:585-593

18. Heit JA, Silverstein MD, Mohr DN (1999) Predictors of survival after deep vein thrombosis and pulmonary embolism: a populationbased, cohort study. Arch Intern Med 159:445-453

19. Sallah S, Wan JY, Nguyen NP (2002) Venous thrombosis in patients with solid tumors: determination of frequency and characteristics. Thromb Haemost 87:575-579

20. Blom JW, Doggen CJ, Osanto S et al (2005) Malignancies, prothrombotic mutations, and the risk of venous thrombosis. JAMA 293:715-722

21. Boersma RS, Jie KS, Verbon A et al (2008) Thrombotic and infectious complications of central venous catheters in patients with hematological malignancies. Ann Oncol 19:433-432

22. El Accaoui RN, Shamseddeen WA, Taher AT (2007) Thalidomide and thrombosis. A meta-analysis. Thromb Haemost 97:1031-1036

23. Zangari M, Siegel E, Barlogie B et al (2002) Thrombogenic activity of doxorubicin in myeloma patients receiving thalidomide: implications for therapy. Blood 100:1168-1171

24. Zangari M, Barlogie B, Thertulien R et al (2003) Thalidomide and deep vein thrombosis in multiple myeloma: risk factors and effect on survival. Clin Lymphoma 4:32-35

25. Schutt P, Ebeling P, Buttkereit U et al (2005) Thalidomide in combination with vincristine, epirubicin and dexamethasone (VED) for previously untreated patients with multiple myeloma. Eur J Haematol 74:40-46

26. Johnson DC, Corthals S, Ramos C et al (2008) Genetic associations with thalidomide mediated venous thrombotic events in myeloma using targeted genotyping. Blood 112:4924-4934

27. Palumbo A, Cavo M, Bringhen S et al (2007) A prospective, randomized, phase III study of enoxaparin versus aspirin versus low-fixed-dose of warfarin in newly diagnosed myeloma patients treated with thalidomide-containing regimens. Blood 110. Abstract 310

28. Costa G, Engle RL Jr, Schilling A et al (1973) Melphalan and prednisone: an effective combination for the treatment of multiple myeloma. Am J Med 54:589-599

29. Plasmati R, Pastorelli F, Cavo M et al (2007) Neuropathy in multiple myeloma treated with thalidomide: a prospective study. Neurology 69:573-581

30. San Miguel J, Blade J, Boccadoro M et al (2006) A practical update on the use of bortezomib in the management of multiple myeloma. Oncologist 11:51-61

31. Richardson PG, Briemberg H, Jagannath S et al (2006) Frequency, characteristics, and reversibility of peripheral neuropathy during treatment of advanced multiple myeloma with bortezomib. J Clin Oncol 24:3113-3120

32. Ghobrial IM, Rajkumar SV (2003) Management of thalidomide toxicity. J Support Oncol 1:194-205 
33. Cavaletti G, Beronio A, Reni L et al (2004) Thalidomide sensory neurotoxicity: a clinical and neurophysiologic study. Neurology 62:2291-2293

34. Mileshkin L, Stark R, Day B et al (2006) Development of neuropathy in patients with myeloma treated with thalidomide: patterns of occurrence and the role of electrophysiologic monitoring. J Clin Oncol 24:4507-4514

35. Kaur A, Yu SS, Lee AJ (2003) Thalidomide-induced sinus bradycardia. Ann Pharmacother 37:1040-1043

36. Fahdi IE, Gaddam V, Saucedo JF et al (2004) Bradycardia during therapy for multiple myeloma with thalidomide. Am J Cardiol 93:1052-1055

37. Bladé J, Esteve J, Rosiñol L et al (2001) Thalidomide in refractory and relapsing multiple myeloma. Semin Oncol 28:588-592

38. García-Sanz R, González-Porras JR, Hernández JM et al (2004) The oral combination of thalidomide, cyclophosphamide and dexamethasone (ThaCyDex) is effective in relapsed/refractory multiple myeloma. Leukemia 18:856-863

39. Mateos MV, Oriol A, Martínez J et al (2008) Bortezomib (Velcade)melphalan-prednisone (VMP) versus velcade-thalidomideprednisone (VTP) in elderly untreated multiple myeloma patients: which is the best partner for velcade: an alkylating or an immunomodulator agent? Blood 112. Abstract 651

40. Hall VC, El-Azhary RA, Bouwhuis S et al (2003) Dermatologic side effects of thalidomide in patients with multiple myeloma. J Am Acad Dermatol 48:548-552

41. Horowitz SB, Stirling AL (1999) Thalidomide-induced toxic epidermal necrolysis. Pharmacotherapy 19:1177-1180

42. Rajkumar SV, Gertz MA, Witzig TE (2000) Life-threatening toxic epidermal necrolysis with thalidomide therapy for myeloma. $\mathrm{N}$ Engl J Med 343:972-973

43. Nijsten T, Meuleman L, Schroyens W et al (2002) Thalidomideinduced morbilliform rash: diagnosis and continuation of therapy, premedicated with methylprednisolone. Dermatology 204:365367

44. Amin N, Brancaccio R, Cohen D (2006) Cutaneous reactions to injectable corticosteroids. Dermatitis 17:143-146

45. Dimopoulos MA, Kastritis E, Rosinol L et al (2008) Pathogenesis and treatment of renal failure in multiple myeloma. Leukemia 22:1485-1493

46. Eriksson T, Höglund P, Turesson I et al (2003) Pharmacokinetics of thalidomide in patients with impaired renal function and while on and off dialysis. J Pharm Pharmacol 55:1701-1706

47. Chen N, Lau H, Kong L et al (2007) Pharmacokinetics of lenalidomide in subjects with various degrees of renal impairment and in subjects on hemodialysis. J Clin Pharmacol 47:1466-1475

48. Pineda-Roma M, Tricot G (2007) High-dose therapy in patients with plasma cell dyscrasias and renal dysfunction. Contrib Nephrol 153:182-194

49. Palumbo A, Boccadoro M (2007) A new standard of care for elderly patients with myeloma. Lancet 370:1191-1192

50. San Miguel JF, Schlag R, Khuageva NK et al (2008) Bortezomib plus melphalan and prednisone for initial treatment of multiple myeloma. New Engl J Med 359:906-917

51. Wang M, Dimopoulos M, Chen C et al (2008) Lenalidomide plus dexamethasone is more effective than dexamethasone alone in patients with relapsed or refractory multiple myeloma regardless of prior thalidomide exposure. Blood 112:4445-4451

52. Sonneveld P, Hajek R, Nagler A et al (2008) Combined pegylated liposomal doxorubicin and bortezomib is highly effective in patients with recurrent or refractory multiple myeloma who received prior thalidomide/lenalidomide therapy. Cancer 112:1529-1537

53. Sidra G, Williams CD, Russell NH et al (2006) Combination chemotherapy with cyclophosphamide, thalidomide and dexamethasone for patients with refractory, newly diagnosed or relapsed myeloma. Haematologica 91:862-863
54. Fonseca R, Stewart AK (2007) Targeted therapeutics for multiple myeloma: the arrival of a risk-stratified approach. Mol Cancer Ther 6:802-810

55. Barlogie B, Pineda-Roman M, van Rhee F et al (2008) Thalidomide arm of total therapy 2 improves complete remission duration and survival in myeloma patients with metaphase cytogenetic abnormalities. Blood 112:3115-3121

56. Dimopoulos MA, Eleutherakis-Papaiakovou V (2004) Adverse effects of thalidomide administration in patients with neoplastic diseases. Am J Med 117:508-515

57. Murphy PT, O'Donnell JR (2006) Thalidomide induced impotence in male hematology patients: a common but ignored complication? Haematologica 92:1440

58. Rajkumar SV, Gertz MA, Lacy MQ et al (2003) Thalidomide as initial therapy for early-stage myeloma. Leukemia 17:775-779

59. Weber D, Rankin K, Gavino M et al (2003) Thalidomide alone or with dexamethasone for previously untreated multiple myeloma. $\mathrm{J}$ Clin Oncol 21:16-19

60. Rajkumar SV, Blood E, Vesole D et al (2006) Phase III clinical trial of thalidomide plus dexamethasone compared with dexamethasone alone in newly diagnosed multiple myeloma: a clinical trial coordinated by the Eastern Cooperative Oncology Group. J Clin Oncol 24:431-436

61. Cavo M, Zamagni E, Tosi P et al (2004) First-line therapy with thalidomide and dexamethasone in preparation for autologous stem cell transplantation for multiple myeloma. Haematologica 89:826-831

62. Rajkumar SV, Hayman S, Gertz M et al (2002) Combination therapy with thalidomide plus dexamethasone for newly diagnosed myeloma. J Clin Oncol 20:4319-4323

63. Osman K, Comenzo R, Rajkumar SV (2001) Deep venous thrombosis and thalidomide therapy for multiple myeloma. $\mathrm{N}$ Engl J Med 344:1951-1952

64. Zervas K, Dimopoulos MA, Hatzicharissi E et al (2004) Primary treatment of multiple myeloma with thalidomide, vincristine, liposomal doxorubicin and dexamethasone (T-VAD doxil): a phase II multicenter study. Ann Oncol 15:134-138

65. Wu P, Davies FE, Horton C et al (2006) The combination of cyclophosphomide, thalidomide and dexamethasone is an effective alternative to cyclophosphamide-vincristine-doxorubicinmethylprednisolone as induction chemotherapy prior to autologous transplantation for multiple myeloma: a case-matched analysis. Leuk Lymphoma 47:2335-2338

66. Barlogie B, Tricot G, Anaissie E et al (2006) Thalidomide and hematopoietic-cell transplantation for multiple myeloma. N Engl J Med 354:1021-1030

67. Neben K, Moehler T, Benner A et al (2002) Dose-dependent effect of thalidomide on overall survival in relapsed multiple myeloma. Clin Cancer Res 8:3377-3382

68. Schey SA, Cavenagh J, Johnson R et al (2003) An UK myeloma forum phase II study of thalidomide; long term follow-up and recommendations for treatment. Leuk Res 27:909-914

69. Anagnostopoulos A, Weber D, Rankin K et al (2003) Thalidomide and dexamethasone for resistant multiple myeloma. Br J Haematol 121:768-771

70. Palumbo A, Bertola A, Falco P et al (2004) Efficacy of low-dose thalidomide and dexamethasone as first salvage regimen in multiple myeloma. Hematol J 5:318-324

71. Baz R, Li L, Kottke-Marchant K et al (2005) The role of aspirin in the prevention of thrombotic complications of thalidomide and anthracycline-based chemotherapy for multiple myeloma. Mayo Clin Proc 80:1568-1574

72. Dimopoulos MA, Hamilos G, Zomas A et al (2004) Pulsed cyclophosphamide, thalidomide and dexamethasone: an oral regimen for previously treated patients with multiple myeloma. Hematol J 5:112-117 
73. Kropff MH, Lang N, Bisping G et al (2003) Hyperfractionated cyclophosphamide in combination with pulsed dexamethasone and thalidomide (HyperCDT) in primary refractory or relapsed multiple myeloma. Br J Haematol 122:607-616

74. Suvannasankha A, Fausel C, Juliar BE et al (2007) Final report of toxicity and efficacy of a phase II study of oral cyclophospha- mide, thalidomide, and prednisone for patients with relapsed or refractory multiple myeloma: a Hoosier Oncology Group Trial, HEM01-21. Oncologist 12:99-106

75. Lee CK, Barlogie B, Munshi N et al (2003) DTPACE: an effective, novel combination chemotherapy with thalidomide for previously treated patients with myeloma. J Clin Oncol 21:2732-2739 